\title{
IMIA Accreditation of Biomedical and Health Informatics Education: Current State and Future Directions
}

\author{
M.W. Jaspers' ${ }^{1}$ J. Mantas ${ }^{2}$, E. Borycki ${ }^{3}$, A. Hasman ${ }^{1}$ \\ 1 Department of Medical Informatics, Academic Medical Center- University of Amsterdam, Amster- \\ dam, The Netherlands \\ 2 Health Informatics Laboratory, National and Kapodistrian University of Athens, Athens, Greece \\ 3 School of Health Information Science, University of Victoria, Victoria, British Columbia, Canada
}

\section{Introduction}

There is a need for professionals able to address biomedical and health informatics (BMHI) issues in health care by the design, implementation, and evaluation of innovative technological solutions, and this need is growing. Fortunately, many academic institutions are making a significant contribution towards training BMHI professionals by offering educational programs in the field.

Educational institutions are currently competing for students. The international status of an institution and its programs is important for students as mobility after graduation (i.e. at the international level) is becoming increasingly important. Graduates from BMHI programs may work locally in their country (e.g. as an analyst or a manager), may move to another country to work (e.g. returning to their home country after completing an education overseas), or may need to work at an international level (e.g. as a consultant for an electronic health record vendor). As well, there is a growing recognition of the internationalization of education. The quality of a higher education institution affects its global status as a leading organization in teaching and research and influences graduates mobility internationally when they seek for employment in the field. Therefore, academic organizations need to be attractive to students researching world leading BMHI academic programs. Quality is currently so important that the global ranking of educational institutions has become a huge business.

The quality of many educational programs is often evaluated by national accred- itation committees. However, only in some countries, do we see that national quality assurance frameworks are sufficiently academically rigorous to ensure universities and their graduates are competitive at an international, higher education, level. Programs that are not academically rigorous at a global level may negatively affect the status of both the institution and the academic program. Therefore, these institutions and academic programs may wish to accredit their programs by an international academic and professional organization as this may enhance the program's reputation and recognition.

An international academic and professional organization has - via its members an excellent insight into the knowledge and skills professionals in the field need to have both nationally and globally. The International Medical Informatics Association (IMIA) is very suited to provide recommendations for education in BMHI due to its international coverage and its work in advancing BMHI competencies at the international level.

Educational institutions that deliver BMHI program include universities (of applied sciences) and colleges, that award academic degrees or professional certifications. To support the continued extension and improvement of high quality educational BMHI programs at a global level, IMIA has established benchmarks and services for the accreditation of these programs worldwide, and acts as an international reference to advise whether these programs meet these benchmarks to be accredited by IMIA. Figure 1 explains IMIA's general aims of accreditation. 


\section{The aims of the International Medical Informatics Association - IMIA - accreditation are:}

1. To assess and ensure the quality of higher education in the field of BMHI

2. To ensure that the level and quality of educational programs offered by academic institutions of various types meet the IMIA recommendations on BMHI competencies

3. To ensure that the process for meeting IMIA recommendations on education in BMHI is recognized by and transparent for the BMHI community

4. To promote a culture of quality and thus encourage the improvement of the quality of higher education in BMHI globally.

Fig. 1 IMIA's general aims of accreditation
There are many national and regional bodies that accredit BMHI programs. One example is the Commission on Accreditation for Health Informatics and Information Management (CAHIIM) that fosters the accreditation of associate and baccalaureate degree programs in health information management and master degree programs in health informatics and health information management professions in the United States [1]. In contrast to local academic program accreditations, initiated by a national or local government, a professional organization, or an academic organization, IMIA aims at offering a global level of accreditation as an independent organization whose focus has been on BMHI education, research, and professionalism for 50 years. Since IMIA is not a national professional association but an umbrella organization with an independent Board of (Vice)-Presidents, IMIA is an international accreditation body at more than arm's length of universities and national local professional associations. As such, IMIA accreditation provides peer assessment at an international level of educational programs and this is acknowledged by all IMIA member societies and member institutions worldwide. Indeed, these local, national, accreditation committees may not be fully capable to judge BMHI programs in terms of depth or breadth of teaching, and research and student competency development at an international level. IMIA accreditation provides educational BMHI programs with information about whether their curriculum, courses, and student competencies upon graduation meet a global standard. Additionally, IMIA accreditation ensures that the contents of the BMHI curriculum being reviewed match the objectives of the program at an international level. IMIA accreditation takes into account the recommendations on education for benchmarking at a global level. These recommendations are focused on the educational needs for professionals to acquire knowledge and skills in information processing and information and communication technology in health care, and cover four domain areas that are recognized globally as explained in Figure 2 (see [2] for further details).

We believe that IMIA accreditation provides a competitive advantage for those programs and students who graduate from such an accredited program. IMIA accreditation also benefits BMHI accredited programs by identifying other academic institutions where there are commonalities and differences with respect to curriculum and research internationally. Such a network of accredited institutions stimulates inter-institutional collaborations within and between countries at a global level. In this paper, we outline and describe the IMIA accreditation framework, share our first experiences associated with the IMIA accreditation process, and outline potential future aims for IMIA accreditation of BMHI programs globally.

\section{IMIA Recommendations on BMHI Education}

In 2006, a task force was established under the auspices of IMIA's Working Group on Health and Medical Informatics Education to consider and undertake any necessary work to update IMIA Recommendations on Education in BMHI [2]. IMIA recommendations are focused on knowledge and skills of BHMI professionals in information processing and information and communication technology. The competencies are described as a three-dimensional framework: 1) professionals in health care (e.g. physicians, nurses, and more globally BMHI professionals), 2) the specialization in BMHI (IT users, BMHI specialists), and 3) the stage of career progression (bachelor, master, and doctorate). Core competencies are defined in terms of knowledge and practical skills for health care professionals as (a) information technology (IT) users and (b) BMHI specialists. Recommendations are given for courses/ course tracks in BMHI as part of educational programs in medicine, nursing, health care management, dentistry, pharmacy, public health, health record administration, and informatics/computer science as well as for dedicated programs in $\mathrm{BMHI}$ (with bachelor, master, or doctor degree).

IMIA recommendations are being used in most universities (including applied sciences universities), colleges, and other educational institutions globally to either establish new programs or to update and modify existing ones. A number of publications report that the implementation of the recommendations was effective without issues leading to presume the document of the recommendations was of adequate quality [3-6]. The accreditation process, effectively applied, could be

\section{The IMIA recommendations on educational needs for BMHI professionals are classified into} the following domain areas:

1. BMHI core knowledge and skills

2. Medicine, health and biosciences, health system organization

3. Informatics/computer science, mathematics, biometry

4. Optional modules in BMHI and from related fields.

Fig. 2 The IMIA recommendations on educational needs for BMHI professionals [see 2]. 
used to monitor the process but beyond to evaluate the process of how recommendations were implemented and may provide IMIA with feedback from the institutions, colleagues, and students.

\section{History and Experiences with IMIA Accreditation}

In 2010, one of the authors (AH) joined the IMIA Board as Vice President (VP) for Special Affairs. One of his tasks was to explore how the regional members of IMIA would consider the possibility that IMIA, as an academic and professional organization, could operate as an accreditation agency. The VP proposed an accreditation procedure inspired from the Netherlands Flemish Accreditation Organization- NVAO [7] and based on quality standards. Country-based accreditation procedures are quite similar and the accreditation procedure that was proposed did not differ much from the ones used in other countries.

Representatives of regional members of IMIA reviewed the proposal and supported the presentation of the IMIA Accreditation proposal at the IMIA General Assembly. Agreement was reached that the IMIA Accreditation procedure [8] would be piloted in a few BMHI programs distributed over the IMIA regions. Both academic programs and programs for higher professional education were invited to volunteer and enter the accreditation process. It was agreed that if the outcome of the trial was positive IMIA could start accrediting BMHI programs.

In 2011, the IMIA General Assembly approved the pilot project. Interest in participating to the pilot emerged immediately and six BMHI (i.e. programs located in South America, Europe, the Middle East, and Asia) volunteered to participate to the pilot. Due to the political situation in its country, one of the programs could not be able to participate.

The IMIA accreditation pilot was coordinated by the VP for Special Affairs. He identified and selected the individuals who would be part of the site visit accreditation committee and participate to site visits. The proposed members were presented to the institution to be accredited and the institution representatives were asked to tell whether they accepted the members of the accreditation committee. Accreditation committee members were always accepted by institutions to be accredited. The site visit accreditation committee was made of a chairman who also acted as secretary, and of the representatives of the member regions that had evaluated the proposal. Additional experts were asked to participate based on their experience in elaborating educational courses and programs in the BMHI field. Experts should be senior academics with ample experience in education and research in Health Informatics. In practice this meant that accreditation committee members were usually BMHI professors. To ensure continuity and standardization of all IMIA accreditation processes, one of the authors (JM), who was also responsible of the first revision of IMIA educational recommendations, participated to most of the site visits. To assess the quality of the IMIA accreditation, an IMIA Accreditation Review Committee was formed, whose duty was to evaluate the quality of the accreditation procedure and to monitor and oversee the pilot. Once all the site visits were completed, the IMIA Accreditation Review Committee reviewed the documentation produced by site visits and provided a final recommendation to the IMIA General Assembly as to whether or not continue the accreditation process.

After the pilot phase, the IMIA Accreditation Review Committee was made responsible for carrying out the accreditation procedure. The IMIA Accreditation Review Committee is chaired by the VP for Special Affairs of IMIA. Other members of the IMIA Accreditation Review Committee include the VP Services of IMIA and the chairman of the IMIA Working Group Health and Medical Informatics Education. The IMIA Accreditation Review Committee reports to the IMIA Board, suggests site visit committee members, and is responsible of monitoring the process and ensuring that information is provided back to the site visit committee that conducted the visit and to the BMHI program that was reviewed for accreditation. When a program is accredited, it receives a written certificate signed by the IMIA President and the IMIA Vice President for Special Affairs. The accreditation of the institution is included in the relevant official register of IMIA. This registration means that the degree awarded by the program is recognized by IMIA for a period of five years, after which the institution can decide to re-accredit its educational program(s). The site visit panel's report and the name of the programs accredited by IMIA are published by IMIA on its website [9].

When a program is in the process of re-accreditation, the new self-assessment report has to show how it has answered the recommendations for improvement made by the site visit committee on the previous review. A limited framework is used for reaccreditation of programs. The limited framework will particularly focus on the substantive quality of the program, including the required learning environment, the teaching staff, and exit qualifications of graduates. Topics that are left out of consideration are: institution-wide quality assurance, staff policy pursued by the institution, and services and facilities as these aspects have already been assessed during the first round of accreditation.

Programs, whose accreditation have been limited in validity because they either totally or partly did not meet all the quality standards, can be accredited on a provisional basis of two years during which they have the opportunity to improve. In this case, IMIA indicates the areas of improvement and provides recommendations on how to remediate the observed issues to meet all quality standards. After these two years, programs are re-evaluated to determine if they meet the recommendations stated in the first review report.

\section{Evaluation of Site Visits and Accreditation Procedure Pilot}

The pilot phase was meant to determine whether the procedure derived from the NVAO was adequate to other countries. It appeared that the procedure worked quite well in different countries in Europe, the Middle East, South America, and Asia. One important challenge emerged during the first site visits where master theses were not written in English language. To obtain the translation in English of 20 theses was not 
deemed feasible. Therefore, when theses were not available in English language, the institution was asked to send an English translation of the summary and table of contents of each thesis. Theses were then discussed during the site visit with the supervisors who could respond to the questions of the site visit committee. An extra day was devoted to the discussion of the theses when they were not written in English language.

Instructions for writing self-assessment reports were not always fully clear. Thus, it was considered to translate these self-assessment reports into the country language of the institution that was asking for accreditation. This was considered as a good idea, but those translations should be taken on by the BMHI society of the member country of the institution. Although writing a self-assessment report takes time and requires the cooperation of quite a number of people, this task was considered very useful both by the institutions participating to the pilot phase and the site visit committee. Indeed, self-assessment reports were providing insight on the quality of the educational endeavour before the site visit had started.

It further became clear that, for transparency reasons, processes, procedures, and competencies of site visit members had to be precisely defined by IMIA as well as the site visit rules of engagement to ensure a clear separation of logistical support and hospitality offered by local institutions based on the diversity of cultures in the IMIA world. The IMIA board decided that site visit members should be experienced biomedical informaticians with the following qualifications: 1) a master or vocational degree, preferably in biomedical informatics, health informatics or affiliated fields, 2) a minimum of five years of teaching experience in a BMHI educational program at the master or vocational degree level, 3) a minimum of three years of experience in establishing educational courses in the BMHI field at the master or vocational degree level. To become a member of an IMIA site visit committee, candidates were asked to submit a Curriculum Vitae showing that he/she has the required qualifications. Candidates were finally selected as site visit committee members by the IMIA accreditation committee (IMIA VP Special affairs, former IMIA president).
Additional remarks of site visit panellists concerned the logistical support provided during site visits. During the pilot test period, site visit panellists participated on a voluntary basis without additional funding or any honorarium. Local institutions were covering only travelling and accommodation costs. It should also be noted that no secretarial support was included by IMIA during site visits and neither was secretarial support given to the site visit panellists or to the Accreditation Review Committee at the IMIA headquarters. This was understandable in a trial period of the accreditation process such as established by IMIA. However, if a professional process was going to be established, secretarial and management level support should be given by IMIA to both the Accreditation Review Committee and the site visit committee members. A lack of this would lead to a suboptimal process.

\section{Modifications of Site Visits and Accreditation Procedure}

The IMIA accreditation process including the format and requirements for self-assessment reports and site visit procedure has been revised on the basis of these first experiences with accreditations of university programs and programs for higher professional education. Institutions opting for IMIA accreditation were found to need more guidance in producing self-assessment reports. The IMIA Accreditation Review Committee reviewed the commentaries of the BMHI programs that participated to the pilot with a focus on the description of what a program should report about and reflect on in a self-assessment report leading to an updated version of self-assessment report guidelines. This version was discussed and agreed upon by the IMIA Board (see Figure 3). The items to be included in the self-assessment report are described in more detail in the information about the Accreditation Procedure and is available via IMIA's website.

Detailed guidelines on the structure of the self- assessment report and required appendices can be found in [8-10]. Further, pilot institutions indicated that they were not well informed regarding the timing and flow of activities and the obligations of parties involved in IMIA accreditation. Based on these comments, a time schedule and flow diagram, explaining the activities and responsibilities of each involved party, were developed. Finally, answers to questions that institutions frequently asked before or during the accreditation process of their programs were also elaborated. Overall, pilot institutions reported that the accreditation of their programs stimulated self-evaluation and self-directed improvement and provided a cost effective review mechanism. Indeed, most of the work was done by experienced site visit members who donated their time and expertise for free. These institutions further believed that IMIA accreditation provided a system for accountability that would enhance the reputation of BMHI programs.

\section{Future Plans for IMIA Accreditation}

In the upcoming years a number of initiatives surrounding IMIA accreditation will be undertaken. Universities, colleges, and member programs that either have received, or are interested in, or are eligible for IMIA accreditation will be sent a survey to learn more about BMHI programs internationally. The aim is to develop a comprehensive catalogue of BMHI programs along with their attributes (e.g. number of students who have completed programs, number of faculties, courses, and specializations). It is expected that the work to develop a database of reviewers for accrediting programs and to organized lectures and workshops for BMHI programs to learn about the benefits of BMHI accreditation and the accreditation process itself will be continued and extended.

\section{Discussion and Conclusions}

The educational initiatives of IMIA emanating from the meetings and conferences organized by the Working Group Health and Medical Informatics Education as early as in 


\section{The self-assessment report should discuss or provide:}

1. The intended end qualifications of the program together with the level and orientation of the program

2. The curriculum (it should also be made clear that the curriculum takes into account the new developments in the relevant scientific disciplines (academic requirements) or professional practice)

3. In which modules the various intended end qualifications are taught, and how a coherent curriculum is ensured

4. The didactic concept and the way in which it is worked out in the program

5. The number of contact hours and self-study hours for each module, spread of study load over the years, examination results, (organization of) student evaluations and results, and how bottlenecks have been tackled

6. The number and competencies of students that enter the program yearly and the percentage of students that actually graduate

7. Information about the regulatory requirements in the country of the program

8. For each module, the number of students that directly pass the module examinations, and the types of feedback given to students; how validity and reliability of exams is assured; the type of staff (professors, teachers with $\mathrm{PhD}$, without $\mathrm{PhD}$, involved in teaching and research etc) involved in education; credentials of teachers (educational performance, research publications, awards); student satisfaction with teachers performance. For vocational training programs, the type of staff and the experience of the staff in practical work

9. The student-staff ratio and administrative staff providing educational support to the program

10. The computer, internet, email, and library facilities

11. The organization of study counselling and support, and the information provision on changes in the program, how to register for examinations, etc.

12. The way quality is carried out and information is provided about the items mentioned above

13. Information about the results of previous evaluations and how the program reacted to possible critique

14. The organization of the internal quality system and the involvement of the various stakeholders

15. An overview of the theses, and the results of possible alumni survey (what were the experiences of the alumni with finding jobs and with working and were they of the opinion that their qualifications are well suited for the jobs they have)

Fig. 3 Facets of the self-assessment report

the 1980's till the early 2000 's provided two major outcomes: educational recommendations and the accreditation process. However, there is a distinctive difference between the two initiatives. Educational recommendations are provided in a document endorsed by IMIA, disseminated and translated into many languages, used by a number of institutions, and cited in a great number of publications. On the other hand, the accreditation initiative is a process defined and endorsed by IMIA, which requires field effort and requires procedures and logistics to be accomplished in a professional way. In this paper, we have provided a brief overview of the accreditation process, a description of the experiences of the sites already accredited, feedback work. So in this way, it is not so much the value of the accreditation procedure that is measured but the outcome of the programs.

With its accreditation system, IMIA aims to guarantee the quality of higher education in BMHI provided by worldwide institutions recognized as socially relevant, and enjoying the trust of students, employers, and society.

\section{Acknowledgements:}

We are very grateful to all our international colleagues, members of site visit committees, who took part to the site visits of programs and institutes during the pilot phase of IMIA accreditation.

\section{References}

1. Commission on Accreditation for Health Informatics and Information Management -CAHIIM: www.CAHIIM.org. Last visited: April 5, 2017.

2. Mantas J, Ammenwerth E, Demiris G, Hasman A, Haux R, Hersh W, et al. Recommendations of the International Medical Informatics Association (IMIA) on Education in Biomedical and Health Informatics. IMIA Recommendations on Education Task Force. Methods Inf Med 2010 Jan 7;49(2):105-20.

3. Mantas J. Implementation of the recommendations in master's courses in health informatics. Stud Health Technol Inform 2012;174:57-61.

4. Marcano-Cedeño A, Wageih MA, Gómez EJ, Mantas J. IMIA Dynamic Accreditation Procedure: Suggestions, Simplicity and Efficiency. Stud Health Technol Inform 2015;213:115-8.

5. Mantas J. Biomedical and Health Informatics Education - the IMIA Years. Yearb Med Inform 2016 Aug 2;Suppl 1:S92-S102.

6. Mantas J, Hasman A. IMIA Educational Recommendations and Nursing Informatics. Stud Health Technol Inform 2017;232:20-30.

7. Netherlands Flemish Accreditation Organ: https:// www.nvao.com/quality-assurance-systems/ netherlands

8. Hasman A, Mantas J. IMIA Accreditation of Health Informatics Programs. Health Inform Res 2013 Sep;19(3):154-61.

9. International Medical Informatics Association: http:// imia-medinfo.org/wp/imia-accreditation-pilot/

10. Mantas J, Hasman A, Shortliffe EH. Assessment of the IMIA educational accreditation process. Stud Health Technol Inform 2013;192:702-6.

\section{Correspondence to:}

M. W. Jaspers

Department of Medical Informatics

Academic Medical Center

University of Amsterdam

The Netherlands

Tel: +31 205665269

E-mail: M.W.Jaspers@amc.nl 